\title{
Mini-Review: SARS-CoV-2 and COVID-19
}

\author{
Dhurgham A .H. Alhasan \\ Department of Microbiology - College of Veterinary Medicine, \\ University of Thi-Qar \\ Thi-Qar, Iraq \\ dhurghamalhasan@gmail.com
}

\author{
Husein A. Husein Al-Saidy \\ Department of Environment and Polluton-Marshes Research \\ Center-University of Thi-Qar \\ Thi-Qar, Iraq \\ husseinali_unix79@yahoo.com
}

https://doi.org/10.32792/utq/utjsci/v8/1/2

\begin{abstract}
On 31 December 2019, the cases of pneumonia caused by unknown etiology had emerged. These cases were reported in Wuhan city, Hubei Province of China. Chinese authorities identified the causative agent and announced to be a novel coronavirus. The tentative name of disease is COVID19, abbreviating of coronavirus disease-19. The incubation period of the disease ranges from 2 to 14 days, however, $80 \%$ of the patients have mild or asymptomatic illness while $15 \%$ and $5 \%$ of the patients had exhibited sever and critical cases respectively. The etiology of COVID-19 was known as SARSCoV-2 and belongs to betacoranviruse as reported by the International Committee on Taxonomy of Viruses (ICTV) especially Coronaviridae Study Group (CSG). In addition, this virus is currently believed to be within bat-coronaviruses besides it possesses a close relationship with SARS-CoV more than MERS-CoV. Although, the majority of the diagnosed patients had symptoms, there were asymptomatic persons who can spread the SARS-CoV-2. Upon the emergence of worldwide distribution of this virus, the WHO had declared it as a global outbreak and pandemic. Unfortunately, at present time, there are neither vaccine and nor an approved COVID19 specific drug against SARS-CoV-2. One of the remarkable pathogenesis mechanistic step of this virus is taking possession of the affinity to angiotensin-converting enzyme 2 (ACE2). This mini-review summarizes the origin and molecular identification of the virus as well as the host immune responses.
\end{abstract}

Keywords-SARS-CoV-2, COVID-19, ACE2, origin.

\section{INTRODUCTION}

On 31 December 2019, the cases of pneumonia caused by unknown etiology. These cases were reported in Wuhan city, Hubei Province of China. On 7 January 2020, Chinese authorities identified the causative agent to be a novel coronavirus and it has the tentative name which is 2019-nCoV, abbreviating of coronavirus disease-19 (Lu et al., 2020; WHO, 2020).It caused severe acute respiratory disease currently is known as coronavirus disease 19 (COVID-19). The virus belongs to Coronaviridae as characterized by the International Committee on Taxonomy of Viruses (ICTV) especially Coronaviridae Study Group (CSG).

Depending on the viral phylogeny and taxonomy as well as the expertise, CSG showed the virus belongs to coronaviruses causing severe acute respiratory syndrome (SARS). Therefore, there is a sisterly relationship clade between 2019-nCoV and SARS-CoVs. For this reason, the virus (2019-nCoV) is known as SARS-CoV-2 (Gorbalenya et al., 2020; WHO, 2020). Relatedly, two pandemics outbreaks had globally been reported were SARS-CoV emerged in China which led to be etiology of SARS in 2020. Also, the Middle East region, Saudi Arabia, had emanating MERS-CoV was a noval betacoronavirus species which caused Middle East respiratory syndrome in 2012 (Zhong et al., 2003; Zaki et al., 2012; de Wit et al., 2016; Arabi et al., 2018).

The ongoing reported common symptoms of COVID-19 are fever, dry cough, throat sore, dyspnea, and fatigue (Cheng et al., 2020; Huang et al., 2020; Wang et al., 2020). The incubation period of the disease ranges from 2 to 14 days, however, $80 \%$ of the patients had mild or asymptomatic illness while $15 \%$ and $5 \%$ of the patients had exhibited sever and critical cases respectively (Prompetchara et al., 2020; Rokni et al.,2020). Asymptomatic persons have a role in spreading SARS-CoV-2, yet they suffer from the symptoms 14 days after the viral infection (Al-Tawfiq, 2020; Rothe et al., 2020). Reports about the increasing the prevalence of asymptomatic viral infections have inclined including rhinovirus influenza virus and coronavirus infections (Camargo et al., 2012; Granados et al., 2015; AlTawfiq and Gautret 2019). Concerning coronavirus asymptomatic MERS-CoV infections average of the various reports was about $9.8 \%$ where it was inclined within the last few years from $0 \%$ to $28.6 \%$ while the serological studies revealed that asymptomatic SARS-CoV infection were up to $13 \%$ (Wilder-Smith et al., 2005).Both in Germany and China reported cases of adults and children of asymptomatic SARS-CoV-2 infections have been issued (Chan et al., 2020; Rothe et al., 2020). This may bring about the assumption of the contribution of these asymptomatic cases in the transmission and wide distribution of the infection.

A. Origin of SARS-CoV-2 and its genetic features:

Website: https://utjsci.utq.edu.iq/index.php/main, Email: utjsci@utq.edu.iq 
The first-ever reported in the modern medical history coronavirus infection was on 1962 in the United States and Britain at the same time where the virus is isolated from patients of natural respiratory tract infection. (Kendall et al.,1962; Monto, 1974). Remarkably, coronaviruses are enveloped and characterized by unusual, large and positivesense RNA genome as well as a unique strategy of the replication as well as the projected spikes on their surfaces (Drexler et al.,2010; Fehr and Perlman, 2015; de Wit et al., 2016; Coutard et al., 2020).The Coronaviridae family belongs to the Nidovirales order. This family embraces Coronavirinae subfamily which has four groups of coronaviruses are Alphacoronavirus, Betacoronavirus, Gammacoronavirus, and Deltacoronaviruses. The Coronaviridae classification is based on the morphology of the viral particles, genome organization, unique strategy of RNA replication, and nucleotide sequence homology (Fehr and Perlman, 2015; Carroll et al., 2016). SARS-CoV-2 belongs to Betacoronavirus group (Lu et al., 2020; Wu et al., 2020; Zhu et al., 2020).

Some members of coronaviruses cause mild respiratory illnesses such as 229E and OC43, HKU1 and NL63 (Corman et al.,2018; Sahin et al., 2020; Zhu et al., 2020). Other coronaviruses are causative agents of severe acute reparatory syndromes like SARS-CoV and MERSCoV which were emerged in China (2002) and Saudi Arabia (2012) respectively (Ge et al., 2013; Arabi et al., 2018;Sahin et al., 2020). In December 2019, the cases of severe acute respiratory syndrome caused by unknown etiology began to be reported in China and was initially known as a 2019nCoV (novel coronavirus) (Shereen et al., 2020; Zhou, F et al., 2020; Zhu et al., 2020). This virus had a relating clade within subgenus sarbecovirus belonging to genus Betacoronavirus. This virus is currently considered as the seventh emerging member of human pathogenic coronaviruses (Lu et al.,2020; Wu et al., 2020; Zhu et al.,2020).

Genetically, coronaviruse genome size is extraordinarily large which has the 26.4-31.7 kb (Woo et al., 2014; Luk et al., 2019). However, the complete genomes of SARS-CoV-2, SARS-CoV, and MERS-CoV were already measured to be $29.9 \mathrm{~kb}, 27.9 \mathrm{~kb}$, and $30.1 \mathrm{~kb}$ respectively (Guo et al., 2020). This genetic closeness was confirmed by sequence analysis which showed that SARS-CoV-2 has $77.5 \%$ and $50 \%$ similarities to SARS-CoV and MERS-CoV respectively (Kim et al., 2020). Moreover, uncovering of the complete genome of SARS-CoV-2 which is built up of (29,903 nucleotides) had revealed that this novel virus is mostly associated (89.1\% nucleotide identical) with a cluster of the SARS-like CoVs especially Betacoronavirus and sarbecovirus which were formerly identified in the bats of China. This indicates the ability of this virus (SARS-CoV-2) to spread from animals into humans as an emerging zoonotic disease (Wu et al., 2020). The genetic material analysis of SARS-CoV-2 has revealed that there is $89.1 \%$ genetic homology with that of bat CoV (bat-SL-CoVZC45) and (99.94\%-99.99\%) of other countries including that of Wuhan outbreak of this novel corona virus (Kim et al., 2020).

Finally, the genetic similarity between SARS-CoV-2 and SARS-CoV is (79.6\%) of their full-length genome sequences as well as the similar pairwise protein sequence of them. They share same host cell entrance receptor /mechanism. ACE2 is the same entranceway receptor when they infect the host cells of the respiratory passages of patients. Consequently, as the protein receptor binding domain (RBD) of SARS-spikes provides the affinity and regulation of species interaction and transmission among humans. RBD analysis had led to the assumption that SARSCoV-2 and SARS-CoV are related in their receptors, natural host (bat) and cell infection. Furthermore, SARS-CoV-2 RBD gives the consistent and compatible interaction between the virus and its host (Shereen et al., 2020; Ren et al., 2020; Wan, et al., 2020; Wu et al., 2020; Zhou, P et al., 2020).

In contrast, dipeptidyl peptidase (DPP)-4 and aminopeptidase $\mathrm{N}$ (APN) receptors of other CoVs are not used by SARS-CoV-2 (Zhou, P et al., 2020). DPP-4 is a particular receptor for MERS-CoV (Prompetchara et al., 2020; Wan et al., 2020) while SARS-CoV-2 and SARS-CoV recognize ACE2. In addition, the spikes, RBDs, and RBM (receptor binding motif) of human MERS-CoV and bat MERS-like Covs have a lower similarity in their sequencing proteins (Wan et al., 2020). Additionally, SARS-CoV-2 and SARS-CoV share similar tissue preference mainly through spreading to the respiratory tract of their victims and a bat is natural host for both (Li et al., 2005; Drexler et al., 2010; Ithete et al., 2013; Guo et al., 2020). SARS-CoV-2 shares the similarity which observed were $79.0 \%$ and $51.8 \%$ of the nucleotide sequence with SARS-CoV and MERS-CoV respectively (Ren et al., 2020).

Regarding bat coronaviruses, researchers had tested 315 bats belonging to seven different species of the bats distributed in the north of Germany. They found that four lineages of their group1 coronaviruses associated with the four verspertilionid bats species including Myotis dasycneme, M. daubentonii, Pipistrellus nathusii, and P. pygmaeus. Also, they showed that German bat coronaviruses have sister pedigree with group (clade) Chinese type I coronaviruses which possessed the relationship with $M$. ricketti (bat) in China. (Gloza-Rausch et al., 2008). This may encourage the hypothesis which emphasizes that 229E and SARS-CoV are ancestors of MERS-CoV through the studied phylogenic relationship between the bat and the mentioned viruses (Becker et al., 2008; Ithete et al., 2013). Furthermore, bat may probably be a reservoir for 229E and NL63 while OC43 and KU1 were thought to be originated from the rodent viruses. Also, ancestors of the OC43 may be transmitted from the camel and swine (Corman et al., 2018).

Previously (2005), SARS-like CoVs had identified within Rhinolophus sinicus, wild horseshoe bats in Chinese Yunnan Province. Later on, in China on 2013, a live isolate of SARS-like CoVs was obtained from the incubated cells of Vero E6 in the bat feces. This isolate ( SARS-like CoVs) was found to have the affinity to ACE2 by its S protein as well as it holds the notable similarity $(95 \%)$ between its genome and that with SARS-CoVs including human and civet infecting ones (Sun et al.,2020).Interestingly, beside the close linkage to bat CoVs, amino acids of NSP7 and E proteins identity of SARS-CoV-2 was found to be $100 \%$ identical that of bat SLCoVZC45. This relationship may support the claim that bats were probably be the host for SARS-CoV-2. In the markets of China, as the bats are considered a commercially selling by which it may lead to getting contact to diverse animal species. Therefore, further indicators and studies are extremely needed to confirm the bat is a reservoir for SARSCoV-2 (Wu et al., 2020). At this paradox, SARS-CoV-2 is 
similar to the human, bat, and civet isolates of SARS-CoV. The relating link revealed $76 \%-78 \%$ of whole protein as well as $73 \%-76 \%$, and $50 \%-53 \%$ of similarity for their RBD, and $\mathrm{RBM}$ respectively. The only exception is the insertion of one amino acid residue however, it occurs in a loop part from the binding piece of ACE2. There is no deleting or inserting changes in the RBM of both viruses including isolates of SARS-CoV collected from human, bat, and civet. In addition, RBM contains 14-ACE2 residues. Among these residues, 9 are completely conservative while 4 are incompletely conservative (Wan et al., 2020).

The genome of SARS-CoV-2 and SARS-CoV besides MERS-CoV has still 50-untranslated region (5'UTR), and open reading frame (ORF )including $1 \mathrm{a}$ and $1 \mathrm{~b}$ (Shereen et al., 2020). RNA 5'two-thirds of coronaviruses contain ORF1ab is encoding to form the replicase polyproteins. RNA 3' third one is encoding to produce forms of the proteins which are nucleocapsid $(\mathrm{N})$, matrix $(\mathrm{M})$, envelope (E) and spike (S) glycoprotein (Luk et al., 2019) as well as producing accessory types of proteins that have interaction with innate immune responses of the host (Perlman and Netland, 2009; Woo et al., 2014; Guo et al.,2020). CoV encoded proteases split the ORF1ab translated product into an enzyme set of the 16 nonstructural proteins (NSP), e.g. RNA-dependent RNA polymerase (RdRp), papain-like proteases (PLpro), helicase (Hel), chymotrypsin-like protease (3CLpro) and two methyltransferases (Perlman and Netland, 2009; Luk et al., 2019). Interestingly, the RNA of alpha and betacoronaviruses contains UUUAAAC, conserved sequence, that maintain the distinctive movement (slippage) of the ribosome to obtain ORF1ab transcription (Drexler et al., 2014).

Additionally, there is a strange location in the spike protein of SARS-CoV-2 has been identified which is not present in the SARS-like coronaviruses. This location is a furin-like cleavage position (Coutard et al., 2020). Moreover, SARS-CoV-2 shares the RBD amino acid sequence with SARS-CoV. Furthermore, SARS-CoV-2 genome contains ORF8 is also most related to the bat SARS-like CoVs (Ren et al., 2020). After the MERS- CoV outbreak, a previous study concluded why the coronaviruses can emerge new species and not only strains or genotypes. There are three reasons for getting this phenomenon. First, unfaithfulness of CoVs -RdRp which leads to occur the mutation (one position per 1000-10000 nucleotides) through their replication. Second, these viruses are characterized by a unique RNA replicating strategy and the randomly transform of the template. Third, genome of coronaviruses is the largest compared with RNA-genome viruses. As a result of these factors, CoVs have further flexibility by which they can modify their genes (Woo et al., 2014).

Evidence of closely related coronavirus strains between distantly related animals supports the hypotheses of interspecies jumping and development of seriously risky epidemic or even pandemic outbreaks. In the wet markets of China where contacting humans with animal food, it is probably to getting viral mutation, recombination, and modification due to mutated genes that may be given. In these markets (Woo et al. ,2006). Regarding MERS-CoV and 229E; dromedary camels represent reservoir host of them, however, MERS-CoV had found the way to infect the human population, then it spread by travelling to be worldwide viral infection (de Wit et al., 2016: Corman et al.,2018).

\section{B. Identification}

COVID19 infection diagnosis is currently performed through using computed tomography (CT) of the chest and symptoms in addition to the case history help in the identification of SARS-CoV-2. Notably, the patients who have mild or no symptoms, their CT scan reflected normal images (Cheng et al., 2020). However, it is still necessary that all suspected patients should be isolated even when they have no SARS-CoV-2 infection evidences. In addition, some patients who had exhibited positive results of the viral RNA test but they did not give rise to an indicative SARS-CoV-2 pneumonia representative images on one hand. Electron micrographs revealed that after three days of virus incubation in the host cell (Vero cells) it spreads in wide range in its organelles particularly in the vesicles. The observed virus size is $70-90 \mathrm{~nm}$ in diameter, however, four days are enough to infect $80 \%$ of the affected tissue (Kim et al., 2020).

On other hand, other patients possess the representative imaging results of SARS-CoV-2 pneumonia but with a negative observation of the viral RNA test. Remarkably, it was observed that the second viral RNA test was done for negative ones, in the first examination may exhibit a positive manifestation during the isolation of the patients. Hence considering of the imaging finding must not be neglected (Zhang et al., 2020). Laboratory investigation for identification of SARS-CoV-2 infection is currently depends on RT-PCR for viral RNA detection where specimens collected from the respiratory tract were used. Two priMERS-CoV and probe were used to detect the gene of E protein. These priMERS-CoVwere forward primer: 5'ACTTCTTTTTCTTGCTTTCGTGGT-3' and reverse primer 5'-GCAGCAGTACGCACACAATC-3' while 5'CY5CTAGTTACACTAGCCATCCTTACTGC-3'BHQ1

represented the probe. For amplification, the steps were performed by $50^{\circ} \mathrm{C} / 15 \mathrm{~min}$. , $95^{\circ} \mathrm{C} / 3 \mathrm{~min}$. and then 45 cycles $/ 95^{\circ} \mathrm{C}$ during $15 \mathrm{~s}$ and $60^{\circ} \mathrm{C} / 30 \mathrm{~s}$ (Huang et al., 2020).

Moreover, two genes were also detected (genes of ORFlab and N genes). Forward primer: CCCTGTGGGTTTTACACTTAA and reverse primer was ACGATTGTGCATCAGCTGA whilst the probe: 5'-VICCCGTCTGCGGTATGTGGAAAGGTTATGG-BHQ1-3'

have interested to detect and amplify the ORFlab. Simultaneously, detection of $\mathrm{N}$ gen has done through using forward primer: GGGGAACTTCTCCTGCTAGAAT; reverse primer: CAGACATTTTGCTCTCAAGCTG, and the probe 5'-FAM- TTGCTGCTGCTTGACAGATT-TAMRA$3^{\prime}$. ORFlab and $\mathrm{N}$ genes were amplified together by RTPCR. The conditions were $50{ }^{\circ} \mathrm{C} / 15 \mathrm{~min}$., $95^{\circ} \mathrm{C} / 5 \mathrm{~min}$. for incubation aspect, 40 denaturing cycles at $94^{\circ} \mathrm{C}$ during $15 \mathrm{~s}$, and $55{ }^{\circ} \mathrm{C} / 45$ seconds to obtain the fluorescence hint (Wang et al., 2020).Then, Ct-value, cycle threshold value was estimated according to National Institute For Viral Diseases Control and Prevention, China . If Ct-value has less than 37 indicates to the positive test and 40 of the value or more denotes to the negative test ( http://ivdc.chinacdc.cn/kyjz/202001/t20200121_211337.Htm 1 ). When Ct-value is $37-39$, this indicates to retesting (Wang et al., 2020). 
To amplify a gene of $R d R p$, the used molecular set was forward primer: 5'GTGARATGGTCATGTGTGGCGG-3'; reverse primer: 5'CARATGTTAAASACACTATTAGCATA-' 3 ; and probe: 5'-CAGGTGGAACCTCATCAGGAGATGC-3' (in 5FAM/3'- BHQ format). Also, the $\mathrm{E}$ protein gene was detected by using forward primer: 5'ACAGGTACGTTAATAGTTAATAGCGT-3';

reverse

primer: ATATTGCAGCAGTACGCACACA-3' and probe: 5'ACACTAGCCATCCTTACTGCGCTTCG-3' (5-FAM/3'BHQ format). The process was performed by conditions of RT-PCR were $50^{\circ} \mathrm{C} / 30 \mathrm{~min}$. to get the reverse transcription, and $95{ }^{\circ} \mathrm{C} / 10 \mathrm{~min}$. for the inactivating the reverse transcriptase, then amplifying process was run by 40 cycles of $95^{\circ} \mathrm{C} / 15 \mathrm{~s}$ and $60^{\circ} \mathrm{C} / 1 \mathrm{~min}$. (Kim et al.,2020). However, another work was done to identify the orfla by which as forward primer:

$5^{\prime}$ AGAAGATTGGTTAGATGATGATAGT-3'; reverse primer: 5'-TTCCATCTCTAATTGAGGTTGAACC-3'; and probe: 5'-FAM-TCCTCACTGCCGTCTTGTTGACCABHQ1-3'. In this molecular target, the style of the internal control was performed by using the genes of human GAPDH that forward primer was 5'TCAAGAAGGTGGTGAAGCAGG-3'; and 5'CAGCGTCAAAGGTGGAGGAGT-3' as reverse primer while probe was 5'-VICCCTCAAGGGCATCCTGGGCTACACTBHQ1-3'.

Sequentially, the RT-PCR cycling conditions were $42^{\circ} \mathrm{C} / 30$ min., followed by $95^{\circ} \mathrm{C} / 10 \mathrm{~min}$., and 40 amplifying cycles including $95^{\circ} \mathrm{C} / 15 \mathrm{~s}$ and $58^{\circ} \mathrm{C} / 45 \mathrm{~s}$. The fluorescence was given by the $58^{\circ} \mathrm{C}$ phase (Lu et al., 2020).

\section{Immune responses:}

Prevailingly, the SARS-CoV-2 and SARS-CoV adhere to the lower parts of the respiratory tract. Then, they infect the ACE2 of the alveolar epithelial cells. Both viruses induce extremely host releasing cytokines which gives rise to a tissue destructive cytokine storm, a mechanism that ends with the failure of organ function. In this context, the viral entrance (respiratory cells entry) provokes the local immune cells for producing cytokines and chemokines to reach pulmonary endothelium (Jiang et al., 2020). However, the cytokine releasing syndrome (CRS) was noticed in severe patients who infected with SARS-CoV-2. Also, lymphocytopenia was investigated in those patients (Shi et al., 2020).

Large amounts of plasma cytokines such as IL1B, IFN $\gamma$ and MCP1 were observed in the critical cases of patients infected with SARS-CoV-2. Those patients have acute respiratory distress syndrome (ARDS) (Huang et al.,2020). The CRS is a one way by which SARS-CoV patients had developed ARDS that may led to their death because of releasing elevated cytokine products such as IFN-a, IL-1b, TNF-a, etc. as well as large concentrations of chemokines e.g., CCL2- CCL5, CXCL8- CXCL10,etc. In a similar way, severe MERS-CoV patients had reported to develop high levels of IL-6 and IFN-a in addition to CCL5,CXCL8 and CXCL-10 in their serum (Li et al.,2020). Totally, the neutrophils, serum IL-6 and c-reactive protein were reported to be increased while lymphocytes decreased.
Additionally, the severity of COVID-19 and patient death associated with those changing levels of the neutrophils and lymphocytes (Prompetchara et al., 2020). Titers of IgG and IgM have recorded an elevated level in the serum of SARS-CoV-2 patients (Zhou,P et al., 2020). Some patients suffer from below normal ratio of leukocytes and other infected persons increased in the leukocyte and neutrophil ratios. Clinically, lymphocytes took a decreasing level in numerous patients. If lymphocyte level became completely decreasing, it can propose to be a factor for diagnosis a new coronavirus. Finally, it was concluded that the SARS-CoV-2 depletes many immune cells leading to inhibit the cellular immunity. Intravenously given immunoglobulines activate anti-infection of severe cases (Chen et al.,2020).

Unfortunately, white blood cell account appeared to be of different ranges among SARS-CoV-2 patients. However, most patients kept normal or decreased value of the account as well as lymphocytopenia. Severe cases had recorded significant elevated ratios of neutrophils while lymphocytes continuously decreased. Besides, the interleukins ( IL-6, IL-10) and TNF- $\alpha$ had the excess (Guo et $a l ., 2020)$. In this context; the majority of patients possessed noteworthy lymphopenia. Also, the neutrophil range and account of WBCs were elevated (Wang et al., 2020) whilst, the laboratory investigation of the Taiwanese first COVID19 case infected with SARS-CoV-2 had the lymphopenia (Cheng et al., 2020).

The serological outcome of the disease involves detection of immunoglobulin $\mathrm{G}(\mathrm{IgG})$ in the patient majority specimens which were found to be induced by the $\mathrm{N}$ protein of SARS-CoV-2 during the early first four days from the development of the disease. Additionally, $\mathrm{S}$ and $\mathrm{N}$ proteins of this virus represent major detected immunogens in the patients infected with this virus (Rokni et al., 2020). Therefore, serological investigations including ELISA and complete blood picture as well as cytokines blood levels. In this context, ELISA test for the detecting IgG and IgM were obtained from the patients infected with SARS-CoV-2.The samples were tested with nucleocapsid protein of the bat SARSr-CoV Rp3 where the results had showed that there is a more than $90 \%$ identical amino acids in the of $\mathrm{N}$ protein for both viruses. Moreover, no results of the cross reaction with other human CoVs (Wu et al., 2020; Zhou, P et al., 2020). The majority of patients possessed noteworthy lymphopenia. Also, the neutrophil range and account of WBCs were elevated (Wang et al., 2020). WBC account appeared the different ranges in the SARS-CoV-2 patients. Most patients kept normal or decreased value of the account as well as lymphocytopenia. Severe cases had recorded significant elevated ratios of neutrophils while lymphocytes continuously decreased . Besides, the interleukins ( IL-6, IL10) and TNF- $\alpha$ had the excess (Guo et al., 2020).

\section{Trial drugs against SARS-CoV-2}

At present time, there are neither vaccine and nor an approved COVID-19 specific drug against SARS-CoV-2. However, the combination of the two protease enzyme inhibitors, lopinavir and ritonavir, had been given for patients who were infected with SARS-CoV-2 in the Chinese hospitals (Huang et al., 2015; Huang et al., 
2020). Researchers showed that there were severe side effects observed when lopinavir and ritonavir were used (Cao et al., 2020). Furthermore, oseltamivir and ganciclovir were also used. However, in order to prevent the secondary infection, the patients were treated by antibiotics such as cephalosporins and quinolones. Additionally and antifungal agents had been used. In emergency, methylprednisolone, and dexamethasone were given to the patients (Chen et al., 2020; Rokni et al., 2020). Concerning the SARS-CoV-2 laboratory investigations, specimens from the respiratory tract were taken to be tested by using RT-PCR for detection of coronavirus genes. Examples of these specimens are throat, nasal and pharyngeal swabs (Huang et al., 2020).

As there are no specific anti-coronavirus drugs; inspired by the studies that recommended lopinavir-ritonavir combination as a promising therapy for both MERS-CoV and SARS-CoV infections (Chu et al.,2004; Spanakis et al., 2014; Kim et al.,2016; Min et al.,2016). Chinese medical specialist decided to try this combination for management of patients with SARS-CoV-2 infection. In a randomized trial a heterogeneous group of 199 Chinese hospitalized adult patients of median age 58 years and $60.3 \%$ them were male with a conformed sever SARS-CoV-2 infection; the two antiretroviral and a protease inhibitors lopinavir-ritonavir combination given in doses of $(400 \mathrm{mg}$ and $100 \mathrm{mg}$, respectively) twice a day for 14 days in a clinical trial study continued for 28 days. This combination had showed no effect on one half of the patients treated with it over the other half managed with standard care. There was no significant difference in the time of clinical improvement for mild to moderate case, mortality rate for severe cases, viral load and different time intervals of positive viral RNA results between the two halves of the patients. The median time of clinical improvement for hospital discharge between the two groups was only one day, however, the residence time in the intensive care unit was significantly shorter 6 days for those on the antiviral drug combination vs. eleven days for those on standard care. In addition, acute kidney damage, secondary infections and demands for invasive/non invasive mechanical ventilation for cases of respiratory failure were lower in patient receiving lopinavir-ritonavir combination. In contrast, more common observed GI side effects were associated with the use of this combination beside the more serious side effects. The two antiviral drug therapy were stopped for $13.8 \%$ of the patients due to adverse effects (Cao et al., 2020).

This may bring about to the assumption that there is no cross receptor binding site equivalency between the old and the SARS-CoV-2 of coronaviruses at least for protease enzyme. However, some of the concerned scientific communities still support the allegation that the effectiveness of this combination of therapy has time-to treatment effects as observed in previous antiviral studies in SARS (Chan et al., 2003). The result of this clinical study of the ineffectiveness of the lopinavir-ritonavir combination was in coincidence of other up-to-date study done in Wuhan of China (Zhou, F et al.,2020) as previously reported for ineffectiveness of lopinavir for treatment of SARS-CoV (Yamamoto et al.,2004). However, it is essential to denote that a previous study proposed a third drug combination treatment like interferon- $\beta 1 \mathrm{~b}$ is required for enhancing the antiviral activity of this combination in SARS-CoV and MERS-CoV infections (Chan et al.,2003; Arabi et $a l ., 2018$ )as used for the treatment of the first Taiwan sever
SARS-CoV-2 case in a 55 years old female patient (Cheng et al.,2020).

\section{CONCLUSIONS}

Up-to-date data emphasize that SARA-CoV-2 is mostly related to SARS-CoV than MERS-CoV. Also, bats may be the animal host reservoir of this virus. Asymptomatically infected persons have a role in the spreading of COVID-19 in the world in different regions. At present, no vaccine and effective drugs against that virus, however, it might be recommended to apply the electricity to kill SARS-CoV-2 as a method to produce a vaccine against COVID-19. Biopsy and post-mortem manifestations are extremely required to provide further information about the virus SARA-CoV-2 pathogenesis and targeted body tissues.

\section{ACKNOWLEDGMENT}

We are grateful for all scientists and researchers especially those who have an interest related to SARS-CoV2. This mini-review represents a simple work to participate in giving knowledge about this virus.

\section{REFERENCES:}

Al-Tawfiq, J.A. (2020). Asymptomatic coronavirus infection: MERS-CoV and SARS-CoV-2(COVID-19). Travel Med. Infect. Dis. 35:1-2. https://doi.org/10.1016/j.tmaid.2020.101608.

Al-Tawfiq, J.A and Gautret, P. (2019). Asymptomatic Middle East respiratory syndrome coronavirus (MERSCoV) infection: extent and implications for infection control: a systematic review. Trav. Med. Infect. Dis. 27:2732.

Arabi, Y.M.; Alothman, A.; Balkhy, H.H.; Al-Dawood, A.; AlJohani, S.; Al Harbi, S. et al., (2018). Treatment of Middle East respiratory syndrome with a combination of lopinavir-ritonavir and interferon-ß1b (MIRACLE trial): study protocol for a randomized controlled trial. Trials. 19 (81): 1-13.

Becker, M.M.; Graham, R.L.; Donaldson, E.F.; Rockx, B.; Sims, A.C.; Sheahan, T. et al., (2008). Synthetic recombinant bat SARS-like coronavirus is infectious in cultured cells and in mice. PNAS. 105 (50): 19944-19949.

Camargo, C.N.; Carraro, E.; Granato, C.F. and Bellei, N. (2012). Human rhinovirus infections in symptomatic and asymptomatic subjects. Braz. J. Microbiol. 43 (4): 16411645 .

Cao, B.; Wang, Y.; Wen, D.; Liu, W.; Wang, J.; Fan, G. et al., (2020). A trial of lopinavir-ritonavir in adults 
hospitalized with severe COVID-19. N. Engl. J. Med.382 (19) :1787-1799.

Carroll, K.C.; Butel, J.S.; Morse, S.A. and Mietzner, T. (2016). Jawetz, Melnick \& Adelberg's Medical Microbiology. 27 ed. McGrw-Hill Education. Pp: 601-605.

Chan, J.F-W.; Yuan, S.; Kok, K-H.; To, K.K-W.; Chu, H.; Yang, J. et al., (2020). A familial cluster of pneumonia associated with the 2019 novel coronavirus indicating person-to-person transmission: a study of a family cluster. Lancet. 395 : 514-523.

Chan, K.S.; Lai, S.T.; Chu, C.M.; Tsui, E.; Tam, C.Y.; Wong, M.M. et al., (2003). Treatment of severe acute respiratory syndrome with lopinavir/ritonavir: a multicentre retrospective matched cohort study. Hong. Kong. Med. J. 9 (6):399-406.

Chen, N.; Zhou, M.; Dong, X.; Qu, J.; Gong, F.; Han, Y. et al., (2020). Epidemiological and clinical characteristics of 99 cases of 2019 novel coronavirus pneumonia in Wuhan, China: a descriptive study. Lancet. 395: 507-513.

Cheng, S-C.; Chang, Y-C.; Chiang, Y-L.; Chien, YC.; Cheng, M.; Yang, C-H.; Huang, C-H.and Hsu, Y-N. (2020). First case of coronavirus disease 2019 (COVID-19) pneumonia in Taiwan. J. Formos Med. Assoc. 119 (3):747751.

Chu, C.M.; Cheng, V.C.; Hung, I.F.; Wong, M. M.; Chan, K. H.; Chan, K .S. et al., (2004). Role of lopinavir/ritonavir in the treatment of SARS: initial virological and clinical findings. Thorax. 59 (3): 252-256.

Corman, V.M.; Muth, D.; Niemeyer, D. and Drosten, C. (2018). Hosts and sources of endemic human coronaviruses. Adv. Virus Res. 100:163-188.

Coutard, B.; Valle, C.; de Lamballerie, X.; Canard, B.; Seidah, N.G. and Decroly, E. (2020). The spike glycoprotein of the new coronavirus 2019-nCoV contains a furin-like cleavage site absent in CoV of the same clade. Antiviral Res. 176: 1-5.

de Wit, E.; Doremalen, N.; Falzarano, D. and Munster, V.J. (2016). SARS and MERS-CoV: recent insights into emerging coronaviruses. Nat. Rev. | Microbiol. 14: 523534.

Drexler, J.F.; Gloza-Rausch, F.; Glende, J.; Corman, V.M.; Muth, D.; Goettsche, M. et al., (2010). Genomic characterization of severe acute respiratory syndromerelated coronavirus in European bats and classification of coronaviruses based on partial RNA-dependent RNA polymerase gene sequences. J. Virol. 84 (21): 11336-11349.

Drexler, J.F.; Corman, V.M. and Drosten, C. (2014). Ecology, evolution and classification of bat coronaviruses in the aftermath of SARS. Antiviral Res. 101:45-56.

Fehr, A. R. and Perlman, S. (2015). Coronaviruses: an overview of their replication and pathogenesis. Methods in Molecular Biology book series, Vol.1282. Chapter 1, Pp:123. DOI: 10.1007/978-1-4939-2438-7_1

Ge, X-Y.; Li, J-L.; Yang, X-L.; Chmura, A.A.; Zhu, G.; Epstein, J.H. et al., (2013). Isolation and characterization of a bat SARS-like coronavirus that uses the ACE2 receptor. Nat. 503 (7477): 535-538.
Gloza-Rausch, F.; Ipsen, A.; Seebens, A.; Göttsche, M.; Panning, M.; Drexler, J.F. et al., (2008). Detection and prevalence patterns of group I coronaviruses in bats, northern Germany. Emerg. Infect. Dis. 14 (4): 626- 631.

Gorbalenya, A. E.; Baker, S.C.; Baric, R.S.; de Groot, R. J.; Drosten, C.; Gulyaeva, A.A et al., (2020). The species severe acute respiratory syndrome-related coronavirus: classifying 2019-nCoV and naming it SARSCoV-2. Nat. Microbiol. 5: 536-544.g/10.1038/s41564-020-0695-Z

Granados, A.; Goodall, E.; Luinstra, K.; Smieja, M. and Mahony, J. (2015). Comparison of asymptomatic and symptomatic rhinovirus infections in university students: incidence, species diversity, and viral load. Diagn. Microbiol. Infect. Dis. 82: 292-296. doi.org/10.1038/s41564020-0695-z

Guo, Y.R.; Cao, Q.D.; Hong, Z.S.; Tan, Y.Y.; Chen, S.D.; Jin, H. J. et al., (2020). The origin, transmission and clinical therapies on coronavirus disease 2019 (COVID-19) outbreak - an update on the status. Military Med. Res. 7 (11): 1-10.

Huang, C.; Wang, Y.; Li, X.; Ren, L.; Zhao, J.; Hu, Y. et al., (2020). Clinical features of patients infected with 2019 novel coronavirus in Wuhan, China. Lancet. 395: 497-506.

Huang, X.; Xu, Y.; Yang, Q.; Chen, J.; Zhang, T.; Li, Z. et al., (2015). Efficacy and biological safety of lopinavir/ritonavir based anti-retroviral therapy in HIV-1infected patients: a meta-analysis of randomized controlled trials. Sci. Rep. 5: 1-8

Jiang, F.; Deng, L.; Zhang, L.; Cai, Y.; Cheung, C. and Xia, Z. (2020). Review of the clinical characteristics of coronavirus disease 2019 (COVID-19). J. Gen. Intern. Med. 35: 1545-1549.

Kendall, E.J. ; Bynoe, M.L. and Tyrrell, D.A . (1962). Virus isolations from common colds occurring in a residential school. Bri. Med. J. 2 (5297): 82-86.

Kim, J-M.; Chung, Y-S.; Jo, H.J.; Lee, N-J.; Kim, M.S.; Woo, S.H. et al., (2020). Identification of coronavirus isolated from a patient in Korea with COVID19. Osong Public Health Res. Perspect. 11 (1):3-7.

Kim, U. J.; Won, E-J.; Kee, S-J.; Jung, S-I. and Jang, H-C. (2016). Combination therapy with lopinavir/ritonavir, ribavirin and interferon- $\alpha$ for Middle East respiratory syndrome. Antiviral Ther. 21 (5):455-459.

Ithete, N.L.; Stoffberg, S.; Corman, V.M.; Cottontail, V.M.; Richards, L.R.; Schoeman, M.C. et al., (2013). Close relative of human Middle East respiratory syndrome coronavirus in bat, South Africa. Emerg. Infect. Dis. 19 (10): 1697-1699.

Li, W.; Shi, Z.; Yu, M.; Ren, W.; Smith, C.; Epstein, J.H. et al., (2005). Bats are natural reservoirs of SARS-like coronaviruses. Science. 310 (5748):676-679.

Li, X.; Geng, M.; Peng, Y.; Meng, L. and Lu, S. (2020). Molecular immune pathogenesis and diagnosis of COVID19. J. Pharmace. Anal. 10 (2):102-108.

Lu, R.; Zhao, X.; Li, J.; Niu, P.; Yang, B.; Wu, H. et al., (2020). Genomic characterisation and epidemiology of 
2019 novel coronavirus: implications for virus origins and receptor binding. Lancet. 395: 565-574.

Luk, H.K.; Li, X.; Fung, J.; Lau, S.K. and Woo, P.C. (2019). Molecular epidemiology, evolution and phylogeny of SARS coronavirus. Infect. Gen. Evol. 71 : 21-30.

Min, C-K.; Cheon, S.; Ha, N-Y.; Sohn, K.M.; Kim, Y.; Aigerim, A. et al., (2016). Comparative and kinetic analysis of viral shedding and immunological responses in MERS patients representing a broad spectrum of disease severity. Sci. Rep. 6:1-12

Monto, A.S. (1974). Coronaviruses. Yale J. Biol. Med. 47: 234-251.

Perlman, S. and Netland, J. (2009). Coronaviruses postSARS: update on replication and pathogenesis. Nat. Rev. Microbiol. 7 (6): 439-450.

Prompetchara, E.; Ketloy ,C. and Palaga, T. (2020). Immune responses in COVID-19 and potential vaccines: lessons learned from SARS and MERS-CoV epidemic. APJAI . 38:1-9.

Ren, L-L.; Wang, Y-M.; Wu, Z-Q.; Xiang, Z-C.; Guo, $\mathrm{L}$;; $\mathrm{Xu}, \mathrm{T}$. et al., (2020). Identification of a novel coronavirus causing severe pneumonia in human: a descriptive study. Chinese Med. J. 133 (9): 1015-1024.

Rokni, M.; Ghasemi, V. and Tavakoli, Z. (2020). Immune responses and pathogenesis of SARS-CoV-2 during an outbreak in Iran: comparison with SARS and MERS-CoV. Rev. Med. Virol. 30 (3):1-6.

Rothe, C.; Schunk, M.; Sothmann, P.; Bretzel, G.; Froeschl, G.; Wallrauch, C. et al., (2020). Transmission of 2019-nCoV infection from an asymptomatic contact in Germany. N. Engl. J. Med. 382 (10): 727-733.

Sahin, A.R.; Erdogan, A.; Agaoglu, P.M.; Dineri, Y.; Cakirci, A.Y.; Senel, M.E.; Okyay, R.A and Tasdogan, A.M. (2020). 2019 Novel coronavirus (COVID-19) outbreak: a review of the current literature. EJMO. 4 (1):17.

Shereen, M.A.; Khan, S.; Kazmi, A.; Bashir, N. and Siddique, R. (2020). COVID-19 infection: origin, transmission, and characteristics of human coronaviruses. J. Adv. Res. 24: 91-98.

Shi, Y.; Wang, Y.; Shao, C.; Huang, J.; Gan, J.; Huang, X. et al., (2020). COVID-19 infection: the perspectives on immune responses. Cell Death. Diff. 27 (5):1451-1454.

Spanakis, N.; Tsiodras, S.; Haagmans, B.L.; Raj, V.S.; Pontikis, K.; Koutsoukou, A. et al., (2014). Virological and serological analysis of a recent Middle East respiratory syndrome coronavirus infection case on a triple combination antiviral regimen. Int. J. Antimicrob. Agents. 44 (6): 528-532.

Sun, Z.; Thilakavathy, K.; Kumar, S.; He, G. and Liu, S. (2020). Potential factors influencing repeated SARS outbreaks in China. Int. J. Environ. Res. Public Health. 17 (5):1633.

Wan, Y.; Shang, J.; Graham, R.; Baric, R.S. and Li, F. (2020). Receptor recognition by the novel coronavirus from Wuhan: an analysis based on decade-long structural studies of SARS coronavirus. J. Virol. 94 (7): 1-9.
Wang, D.; Hu, B.; Hu, C.; Zhu, F.; Liu, X.; Zhang, J. et al.,(2020). Clinical characteristics of 138 hospitalized patients with 2019 novel coronavirus-infected pneumonia in Wuhan, China. JAMA.323 (11):1061- 1069.

Wilder-Smith, A.; Teleman, M.D.; Heng, B.H.; Earnest, A.; Ling, A.E. and Leo, Y.S. (2005). Asymptomatic SARS coronavirus infection among healthcare workers, Singapore. Emerg. Infect. Dis. 11 (7): 1142- 1145.

Woo, P.C.Y; Lau, S.K.P and Yuen, K-Y.(2006). Infectious diseases emerging from Chinese wet-markets: zoonotic origins of severe respiratory viral infections. Curr. Opin. Infect. Dis. 19 (5): 401-407.

Woo, P.C.Y.; Lau, S.K.P.; Huang, Y. and Yuen, K.Y. (2014). Coronavirus diversity, phylogeny and interspecies jumping. Exp. Biol. Med. 234 (10):1117-1127.

World Health Organization, WHO .(2020). Coronavirus disease (COVID-2019) situation reports. https://www.who.int/docs/defaultsource/coronaviruse/situation-reports/20200121-sitrep-12019 ncov.pdf?sfvrsn=20a99c10_4.

Wu, F.; Zhao, S.; Yu, B.; Chen, Y-M.; Wang, W.; Song, Z-G. et al., (2020). A new coronavirus associated with human respiratory disease in China. Nat. 579:265-269.

Yamamoto, N.; Yang, R.; Yoshinaka, Y.; Amari, S.; Nakano, T.; Cinatl, J. et al., (2004). HIV protease inhibitor nelfinavir inhibits replication of SARS-associated coronavirus. Biochem. Biophys. Res. Commun. 318 (3):719725

Zaki, A.M.; van Boheemen, S.; Bestebroer, T.M.; Osterhaus, A.D. and Fouchier, R.A. (2012). Isolation of a novel coronavirus from a man with pneumonia in Saudi Arabia. N. Engl. J. Med. 367 (19):1814-1820.

Zhang, H-W.; Yu, J.; Xu, H-J.; Lei, Y.; Pu, Z-H.; Dai, W-C. et al., (2020). Coronavirus international public health emergencies: implications for radiology management. Acad. Radiol. 27 (4):463-467.

Zhong, N.S.; Zheng, B.J.; Li, Y.M.; Poon, L.L.; Xie, Z.H.; Chan, K.H. et al., (2003). Epidemiology and cause of severe acute respiratory syndrome (SARS) in Guangdong, People's Republic of China, in February, 2003. Lancet. 362: 1353-1358.

Zhou, F.; Yu, T.; Du, R.; Fan, G.; Liu, Y.; Liu, Z. et al., (2020). Clinical course and risk factors for mortality of adult in patients with COVID-19 in Wuhan, China: a retrospective cohort study. Lancet. 395:1054-1062.

Zhou, P.; Yang, X-L.; Wang, X-G.; Hu, B.; Zhang, L.; Zhang, W. et al., (2020). A pneumonia outbreak associated with a new coronavirus of probable bat origin. Nat. 579:270-273.

Zhu, N.; Zhang, D.; Wang, W.; Li, X.; Yang, B.; Song, J. et al., (2020). A novel coronavirus from patients with pneumonia in China, 2019. N. Engl. J. Med. 382 (8):727733. 